women to identify and escape from abusive relationships and the cycle of violence. In New Zealand, several hundred women, and their children, are denied access to women's refuge each year because they are perceived to have substance abuse or mental health problems. Other women are using mental health and drug and alcohol services that are only treating/responding to the presenting symptoms not acknowledging the abuse that these women are, or have been, experiencing. Other services legal, social services etc - also fail to help and protect women who are mad or difficult. A small, voluntary group of women (Homeworks Trust) have been advocating for these women and a system wide constructive response to their problems and need for safety. Over the past few years they have developed a range of advocacy resources and strategies including interactive websites, a teaching resource, DVD and engaging in a town planning competition. This paper will demonstrate the resources that have been developed, discuss the theory behind the advocacy decisions that have been made, why the group aims for systemic change rather than direct service provisionand discuss how a small group of committed advocates, with very few resources, can make a considerable difference.

\title{
0491 HE DROVE ME MAD - ADVOCACY STRATEGIES TO ADDRESS THE NEEDS OF WOMEN DRIVEN MAD BY DOMESTIC VIOLENCE
}

D Hager* Correspondence: Homeworks Trust, (home) PO Box 20710, Glen Eden, Waitakere City 0641, New Zealand

10.1136/ip.2010.029215.491

Experiencing abuse in a domestic setting can cause women to become mentally ill and to abuse drugs and alcohol. Domestic violence and related services perform a crucial role in helping 